\title{
Variability of heat and salinity content in the North Atlantic in the last decade
}

\author{
V. O. Ivchenko ${ }^{1}$, N. C. Wells ${ }^{1}$, D. L. Aleynik ${ }^{2}$, and A. G. P. Shaw ${ }^{1}$ \\ ${ }^{1}$ National Oceanography Centre Southampton, University of Southampton Waterfront Campus, European Way, \\ Southampton SO14 3ZH, UK \\ ${ }^{2}$ Scottish Association for Marine Science, Scottish Marine Institute, Oban, PA37 1QA, UK
}

Received: 20 July 2009 - Published in Ocean Sci. Discuss.: 4 September 2009

Revised: 14 June 2010 - Accepted: 29 June 2010 - Published: 16 July 2010

\begin{abstract}
The analysis of the heat and salinity contents has been made for the Northern Atlantic for the decade between January 1999 and December 2008. This analysis is based on the Argo profiling data for the upper $2000 \mathrm{~m}$. Basin-averaged values of heat content deviation (HCD) and salinity content deviation (SCD) are robust and stable. The HCD and SCD demonstrate positive trends in the last decade in the upper $2000 \mathrm{~m}$ of the North Atlantic. The linear trend of HCD and SCD are $(11.14 \pm 3.17) \times 10^{20} \mathrm{~J} / \mathrm{yr}$, and $(2.80 \pm 1.17) \times 10^{13} \mathrm{~kg} / \mathrm{yr}$, respectively. Both trends are significant at $95 \%$ level of significance.
\end{abstract}

\section{Introduction}

The ocean salinity and especially heat content are the major parameters characterizing the state of the climate system. The World Ocean has a heat capacity much higher than the atmosphere (more than three orders of magnitude) and therefore it plays an important role in the global heat content changes of the earth climate system (Levitus et al., 2005; Lyman et al., 2006).

The salinity content in the ocean mainly depends on fresh water fluxes from evaporation/precipitation and from the melting/freezing ice. The local heat and salinity contents are linked to the dynamical processes, as well. Global warming results in melting of continental and sea ice. Curry and Mauritzen (2005) have demonstrated that the northern North Atlantic (i.e. the Nordic Seas and Subpolar Basins) were diluted by an extra $19000 \pm 5000$ cubic kilometers of freshwater influx between the mid 1960's and the mid 1990's. Further-

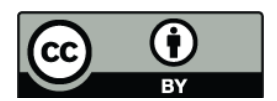

Correspondence to: V. O. Ivchenko (voi@noc.soton.ac.uk) more a significant change in salinity content deviation may result in a substantial change of the meridional circulation (thermohaline circulation), which can drastically change the meridional heat flux.

Is the ocean warming or cooling, what are the mechanisms responsible for this change, and how good the estimation of warming/cooling trends is remain important problems. Past studies have found periods of warming and cooling for the globe as well as in specific regions of the oceans. The number of studies demonstrate the general warming of the ocean as a whole and in its subregions in the recent years. Levitus et al. (2000) made an estimation of the warming of the World Ocean, between the surface and $3000 \mathrm{~m}$ for the period between the mid 1950's and mid 1990's, of $2 \times 10^{23} \mathrm{~J}$. In all oceans a substantial change in heat content occurred in the 300 to $1000 \mathrm{~m}$ layers; moreover, in the North Atlantic such strong changes also happen at depths greater than $1000 \mathrm{~m}$. Analysis of the surface temperature for 140 years between 1861 and 2000 by Folland et al. (2001) also have shown a global surface temperature increase of $0.61^{\circ} \pm 0.16^{\circ} \mathrm{C}$. Willis et al. (2004) estimated a global, interannual variability in the upper ocean heat content, temperature, and thermosteric expansion by combining the altimetric data with in situ temperature profiles. In the period between 1993-2003 the global heat content in the upper 750 $\mathrm{m}$ increased by about $0.92 \times 10^{23} \mathrm{~J}$. Levitus et al. (2009) has revisited global heat content from 1955-2008 and found a linear trend of $13.5 \times 10^{22} \mathrm{~J} / \mathrm{yr}$ in warming between $0-750 \mathrm{~m}$ in the North Atlantic. This warming was not uniform, for example they found that the Atlantic and Pacific ocean heat content decreases after 2005-2006 whereas the Indian ocean does not.

Polyakov et al. (2005) demonstrate substantial changes in temperature and salinity over the North Atlantic in the last Century. They used oceanographic measurements from three

Published by Copernicus Publications on behalf of the European Geosciences Union. 
different Centres, i.e. the National Oceanographic Data Center (NODC), the WOCE data and observations from Arctic and Antarctic Research Institute (St. Petersburg). They found that multidecadal fluctuations on time scales of 50-80 yr are prevalent in the upper $3000 \mathrm{~m}$ of the North Atlantic. Spatially averaged temperature/salinity from two layers, i.e. between 0-300 $\mathrm{m}$ and $1000-3000 \mathrm{~m}$ vary in opposition: persistent periods of cooling/freshening (or warming/salinification) in one layer are generally associated with opposite behavior in another. This is generally consistent with behavior of meridional overturning circulation.

Lozier et al. (2008) evaluated a gain in the North Atlantic heat content over past 50 years by using historical hydrographic station data. They found a basinwide increase heat content for this period of time not to be uniform, showing warming of the tropics and subtropics, but cooling in the subpolar ocean.

A number of studies have shown the importance of the northern part of the North Atlantic, because of strong convection (Curry et al., 1998; Dickson et al., 1996, 2002). The northern subdomains of the Northern Atlantic, and particularly Labrador sea, demonstrates significant variations of temperature and salinity in the past several decades (Yashayaev, 2007). The main process responsible for the cooling and freshening of this area is the deep winter convection. When winter convection has lost its strength, the Labrador Deep Water layer appears to lose "communication" with the mixed layer above (Yashayaev, 2007). As a result, its volume decreased while gaining heat and salt from the intermediate waters outside the Labrador Sea. Sarafanov et al. $(2007,2008)$ show positive trends in temperature and salinity in the intermediate waters of the eastern subpolar North Atlantic (approximately between $36^{\circ} \mathrm{W}$ and $6^{\circ} \mathrm{W}$ at $53^{\circ} \mathrm{N}(1992-2002)$ and $60^{\circ} \mathrm{N}(1997-2005)$, and in the deep waters (1997-2006) (Irminger Sea and Iceland Basin).

One of the important problems in climate dynamics is to understand how the signals are transmitted from the surface to the deep ocean and then distributed throughout the basin (Potter and Lozier, 2004). Leadbetter et al. (2007) has shown that in the mid North Atlantic $\left(36^{\circ} \mathrm{N}\right)$ cooling of the upper waters and warming of the intermediate waters between 1959 and 1981, were reversed between 1981 and 1985. The changes in the upper $800 \mathrm{~m}$ waters were principally due to a vertical displacement of the neutral density surface. In the intermediate waters (below $800 \mathrm{~m}$ ) water mass changes become more important.

Heat content analyses (e.g. Levitus et. al., 2001; Willis et al., 2004) have been shown to be subject to biases. One was a cold bias in some Argo floats whilst a warm bias was introduced from XBT records (Gouretski and Koltermann, 2007; Willis et.al., 2009). Lyman et al. (2006) demonstrated a significant cooling of ocean in between 2003 and 2005. However, in the following study by Willis et al. (2009) it was shown that the cooling reported by Lyman et al. (2006) was an artifact caused by both the XBT warm bias and the cold bias in the Argo data. These corrections have reduced the decadal variability in the heat content records from 1955 to 2008, but have not changed the long term trend (Levitus et al., 2009).

The neighboring regions to the North Atlantic can also influence the heat/salinity contents of the region. Potter and Lozier (2004) have shown that the Mediterranean outflow waters are an important contributor to the climatological changes of temperature and salinity at intermediate depths of the mid latitude North Atlantic. They noted that the warming and/or salinification of Mediterranean surface waters are density compensated.

A good quality merged data set requires that the distribution of the observations in the basin has to be dense enough for an adequate representation. The more dynamically active subdomain (e.g. the Gulf Stream area) with high eddy kinetic energy should have much higher density cover than other regions. However, the density of Argo observations depends not only on the initial position but on the dynamics, as well. The most difficult regions are the strongly dynamical regions (with high kinetic energy of mean flow, and eddy kinetic energy), since the buoys can be moved over a long distance in a short period of time.

Resnyansky et al. (2010) made a statistical analysis of space variability of temperature and salinity data of the Argo profiles in the World Ocean and their subregions between January 2005 and December 2007. They confirm the continuing general warming, however with a pronounced geographical and vertical nonuniformity. The ratio of signal to noise $\mu$ is between 1.5 to 5.7. This ratio is reasonably high and much higher than that based on previous XBT data: $\mu$ is between 0.5 and 1.5 (White and Bernstein, 1979), $\mu$ is about 1 in the upper 400m of World Ocean (White, 1995), and $\mu$ is between 0.5 to 2.9 for different subregions of tropical Pacific (Meyers et al., 1989), but with values of about 1 prevail (Resnyansky et al., 2010). Schukman et al. (2009) used the Argo data for 2003-2008 and found oceanic warming of $0.77 \pm 0.11 \mathrm{~W} / \mathrm{m}^{2}$ in the upper $2000 \mathrm{~m}$ of the World Ocean. Heat content has large interannual fluctuations in some places of the World Ocean. It is important to note that they did not find significant freshwater rate for the global average, however they did find a signal dominated by interannual variability.

The main aim of this study is to calculate heat/salinity content in the Northern Atlantic and its variability during the "Argo" project (i.e. since 1999), by comparing these values with climatology and estimating their significance.

In this study we use the difference between Argo observations and climatology from Stephens et al. (2002) which allows us to produce deviations of heat/salinity contents, which is referred to as $\mathrm{HCD} / \mathrm{SCD}$, respectively.

The data and method is described in Sect. 2, stability of results in Sect. 3, deviations of heat and salinity contents and their trends in Sect. 4, and summary and discussion in Sect. 5. 

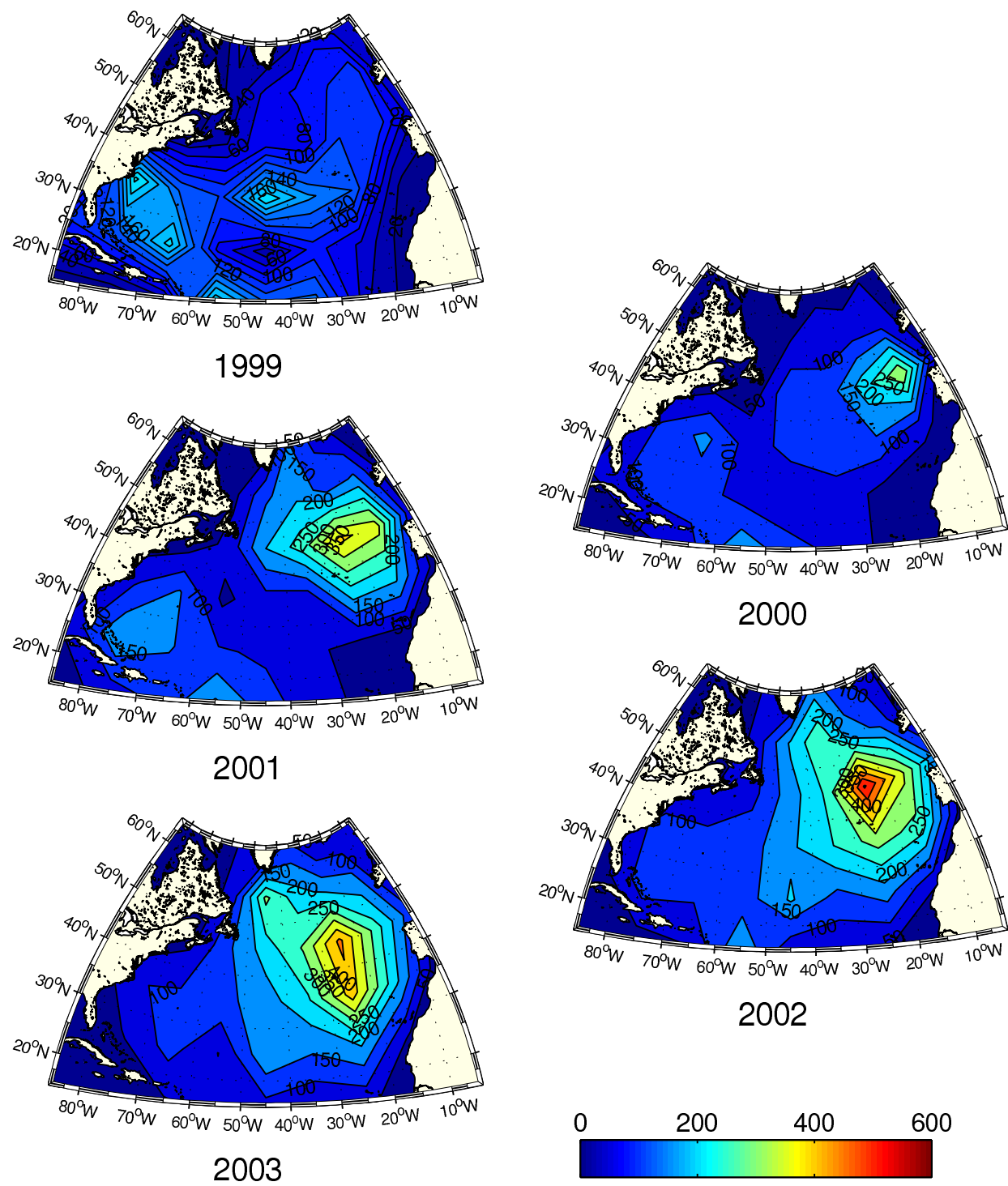

Fig. 1. The number of profiles in the $10^{\circ}$ boxes for each year (1999-2003) after the quality control was applied.

\section{Data and method}

The Argo temperature and salinity profiles were used as our data for the calculations of anomaly (deviation) of heat content (HCD) and anomaly (deviation) of salinity content (SCD). For the analysis we select the period between January 1999 and December 2008 for the area between $10^{\circ} \mathrm{N}$ and $70^{\circ} \mathrm{N}$. The coverage of the Northern Atlantic is not uniform where the maximum number of profiles occur within the vicinity of the central, and especially the eastern region, while minimum number of profiles occur along the coasts (see Figs. 1-2). The amount of temperature profiles per month at the surface increased from 200-300 in 1999 toward 400 in 2001 and 800 in 2008 (Fig. 3). There were less than 100 salinity profiles per month available at the surface before 2001, while in 2008 its reached $700-800$ per month. The number of the accepted data strongly depends on the depth, reducing from the surface by $10-15 \%$ at $500 \mathrm{~m}$, and by 25 $30 \%$ at $1500 \mathrm{~m}$, and decreases further down.

From the official Argo web-site 74958 vertical profiles of temperature and 59485 profiles of salinity were obtained from the site ftp://ftp.ifremer.fr/ifremer/argo/geo/ atlantic_ocean (delayed mode). An Argo profile is excluded from the analysis if it belongs to one of three categories:

- It has not passed the quality control provided by Argo data centre.

- It belongs to the officially published lists of the floats with uncorrectable pressure bias, particularly data obtained from a SOLO. float with FSI CTD (Argo Program WHOI) or APEX floats with APF8 controller board. 

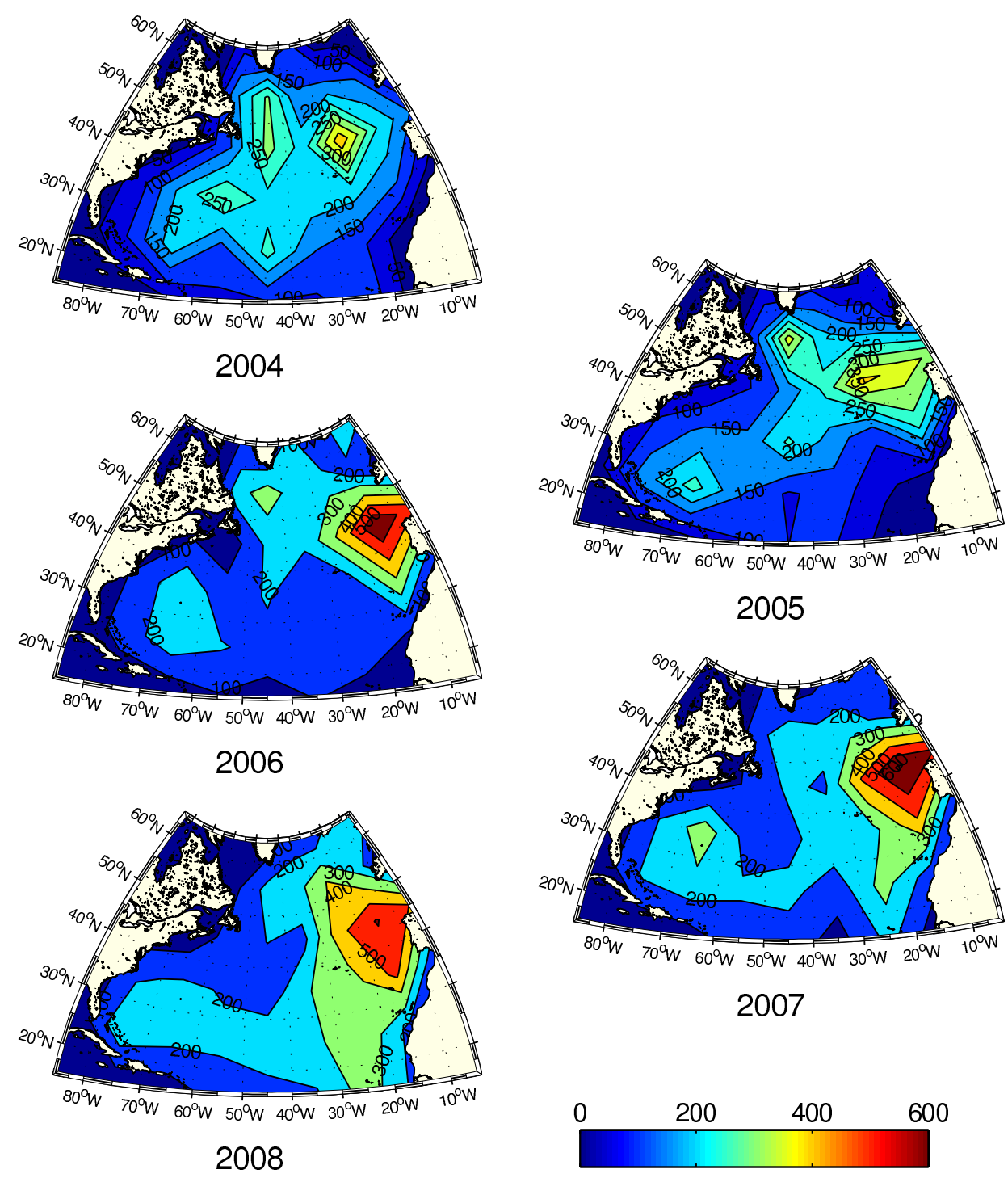

Fig. 2. The number of profiles in the $10^{\circ}$ boxes for each year (2004-2008) after the quality control was applied.

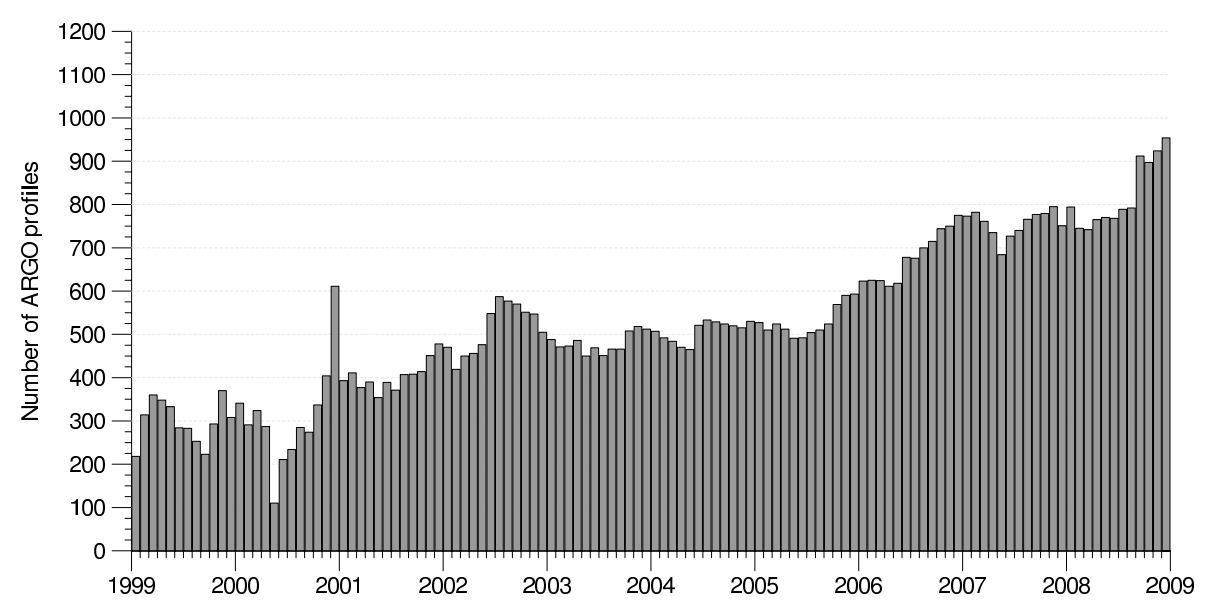

Fig. 3. The temporal distribution of the available Argo data between January 1999 and December 2008. 
- It has not passed our own quality control.

The initial Argo data passed the intensive quality control procedures described in Coatanoan et al. (2005) and Wong et al. (2006). These procedures include automated tests, visual control and objective analyses, applied both daily and weekly. Automated real-time tests verify the following parameters: date, position, speed, global ranges, spikes, density inversions and sensors drifts. The visual quality control performed by operators at the Coriolis Centre includes a comparison of a current profile against neighboring profiles, platform speed, density profile, T/S diagrams, its climatology and associated standard deviation. To detect gross errors and the setting of the quality flags for each profile the results of an objective analysis are taken into account. The Centre uses an objective analysis scheme based on the optimal estimation methods described in Bretherton et al. (1976). Profiles only with the appropriate quality control flag provided by the originators were downloaded and stored in our data set.

Regarding the second category, in February 2007 the Argo community was informed that profiles from Argo buoys deployed by WHOI program (i.e. SOLO floats with FSI CTD) may have pressure offset errors. Updated list of "uncorrectable" platforms was announced in October 2007 at http://www-argo.ucsd.edu/Acpres_offset2.html. Another list of suspicious profiles related the drift in the pressure sensors in several APEX profiles was published in December 2008 at the CSIRO web site: http://www.marine.csiro.au/ $\sim$ cow074/quota/argo_offsets.htm. All "uncorrectable" observations from these types of instruments were removed from initial data set.

The following procedures were used in our own quality control (third category). The differences between the observed (Argo) values and monthly climatology (Stephens et al., 2002) were calculated by subtracting from the observed value the climatological value which was obtained by interpolation (a) temporally to the moment of observation between neighboring months, and (b) geographically to the point of observation (surfacing of the float). Similarly the deviation of heat/salinity content is the calculated heat/salinity content from which the climatological heat/salinity content is subtracted.

The criterion for eliminating profiles from the data set was four standard deviations (SD) from the monthly climatological values. This criterion can be compared with other values used in similar research. In some studies (Levitus et al., 1994; Lozier et al., 1995) a criterion of between 2.3 and 3 SD's has been applied. However, it has been shown (Levitus et al., 2000; Willis et al., 2004; Roemmich and Gilson, 2009) that a larger criterion between 3 and 6 SD gives robust results.

The temperature and salinity anomalies fields were calculated with an objective analysis scheme, based on Gandin (1965) and Bretherton et al. (1976). This scheme uses the Gauss-Markov theorem, which gives a linear esti- mate that is unbiased and is optimal in the least squares sense. Another strong assumption required that the covariance of the data be Gaussian. The scheme used in this study is similar to Lavender et al. (2005). The correlation length scales are prescribed constant values and in this study we applied $L=350 \mathrm{~km}$ in both northward and eastward directions. This is more than twice the value used by Lavender et al. (2005), but it is necessary because of the low spatial resolution of the Argo data. To test the influence of the criterion (i.e. four SD) for eliminating profiles, we compared a range between 2 and $3 \mathrm{SD}$ with a range between 5 and $6 \mathrm{SD}$. It is been found that the signals are smoother and the oscillations are of lower amplitude with a range between 2 and 3 SD compared with a range between 5 and $6 \mathrm{SD}$. However, the overall shape of the signal shows good correspondence between the two cases. The main results in terms of the sign of the anomaly and the trend in warming or cooling, remain similar if the criterion of the quality control is between 2 and $6 \mathrm{SD}$, and therefore the results are robust to these changes.

The climatology used in our study (i.e. Stephens et al., 2002) is based on historical hydrographical data from the end of the 1890's up to 2001. The majority of this data comes from the last half of the 20th Century, and therefore is most representative of this latter period. The standard deviation has been calculated by using a total of 120 samples, i.e. 12 months multiplied by 10 years. HCD and SCD were calculated for $10^{\circ} \times 10^{\circ}$ in latitude and longitude boxes and for all layers between the surface and $2000 \mathrm{~m}$ with the vertical step of $25 \mathrm{~m}$. Additional details about our quality control and objective analysis can be found in Ivchenko et al. (2006, 2007, 2008).

The HCD and SCD data are analysed using a number of techniques. The first, is calculating a linear trend using the least squares approach, where the error estimates are at the 95\% confidence interval, that are significantly different from zero. We will call this model Linear Trend (LT). Second, we then add a sinusoid to this linear model where we call this new model, Linear Trend Plus Oscillation (LTPO). Third, we carry out cross-correlations on pairs of time series, where the error estimates of the correlations are at the $95 \%$ confidence interval, where the null hypothesis assumes that there is no correlation between each pair of time series. The effective degrees of freedom is calculated for each pair of time series, where the coherence and autocorrelation of the data is taken into account when estimating the degrees of freedom (Emery and Thomson, 1998).

The main LTPO model equation is:

$\operatorname{Obs}(t)=\operatorname{Model}(t)+\operatorname{Res}(t)$,

where $\operatorname{Obs}(t)$ is the observed heat/salinity content deviation at time $t, \operatorname{Model}(t)$ is the LTPO model:

$\operatorname{Model}(t)=\beta_{1}+\beta_{2} t+\beta_{3} \cos (\omega t)+\beta_{4} \sin (\omega t)$, 


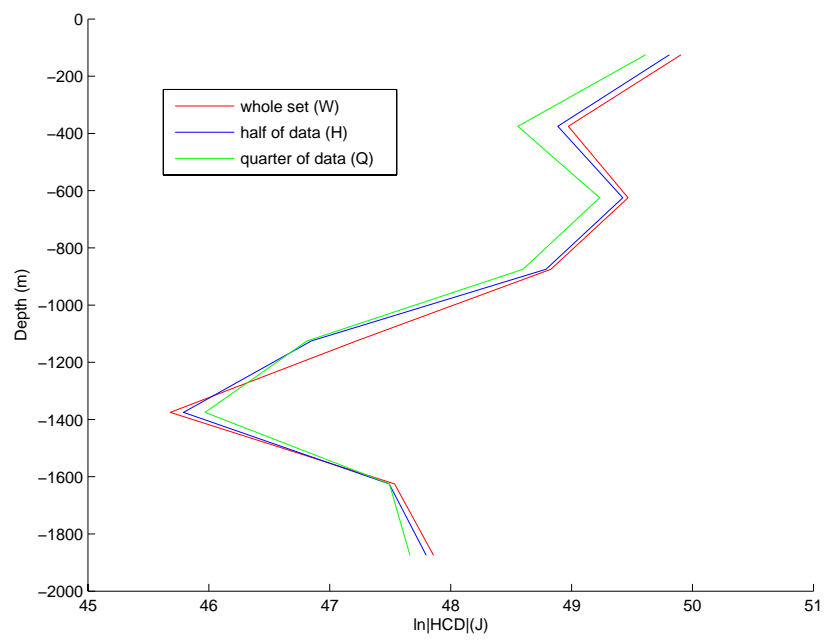

Fig. 4. Anomaly of heat content of the North Atlantic for the upper $2000 \mathrm{~m}$. The red, blue and green curves represent the value of the whole set, $50 \%$ and $25 \%$, respectively. The vertical discretisation is $250 \mathrm{~m}$. The horizontal axes is the natural logarithm of the absolute value of the HCD in Joules.

where $\beta_{1}$ - constant, $\beta_{2}$ - linear trend, $\beta_{3}$ and $\beta_{4}$ - parameters from the $\mathrm{N}$-year sinusoid. $\omega=\frac{2 \pi}{N} ; \operatorname{Res}(t)$ is a residual term (i.e. difference between observations and LTPO model).

$\operatorname{Amp}=\left(\beta_{3}^{2}+\beta_{4}^{2}\right)^{1 / 2}$,

where Amp is an amplitude of oscillation (sinusoidal).

To calculate percentage of variance explained (PVE) we are using the following expression:

$\mathrm{PVE}=\left(1-\frac{\operatorname{Var}(\mathrm{Res})}{\operatorname{Var}(\mathrm{Obs})}\right) \cdot 100 \%$,

where Var is variance.

The reliability of LTPO, (Eqs. 1-2) is calculated by looking at the percentage of variance explained (PVE) by the model with respect to the HCD and SCD observations (see Eq. 4). The Nyquist frequency for these time series are five years and therefore only a period of five years or less is considered for Eqs. (1-4). Preliminary results revealed that the highest PVE value corresponds to seasonal variability and thus the one year sinusoid is used for these analysis.

\section{Stability of results}

By stability we mean that the results should not be sensitive to a small variation in the number or the density of the profiles. One possible way for the estimation of the stability of the obtained results is to separate the whole set of profiles into several subsets and calculate the values of HCD and SCD for each such subset. One can suppose, that the general

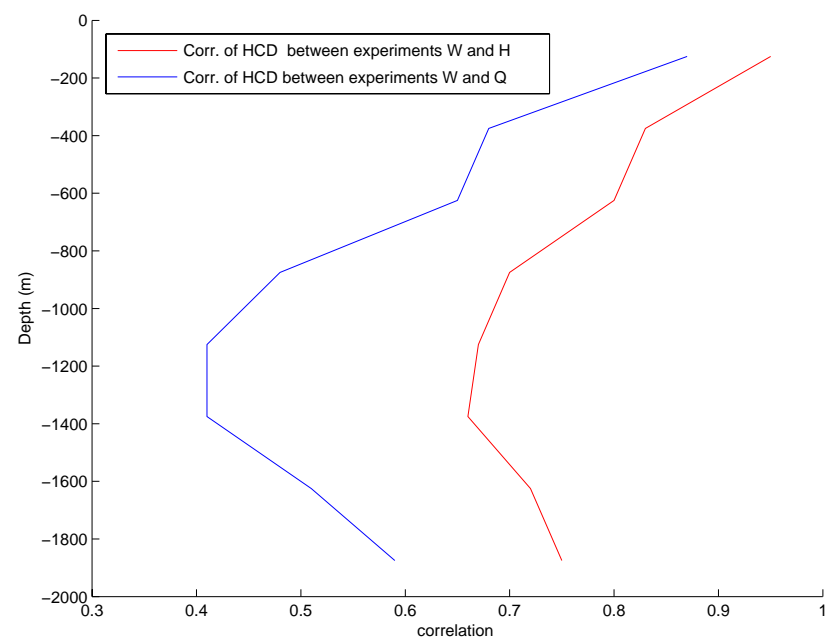

Fig. 5. Correlations between HCD for the whole set and $50 \%$ of data (red curve) and between whole set and $25 \%$ of data (blue curve). HCD is the averaged value of the North Atlantic, the vertical discretisation is $250 \mathrm{~m}$.

results are stable if the corresponding values are close to each other (i.e., high correlation values that are statistically significant). In this study we estimate HCD and SCD values for the whole set (experiment $W$ ), half set $(H)$ and quarter set of the data $(Q)$. In the experiments $H$ and $Q$ half and $3 / 4$ of the data were removed randomly from the whole set. Figure 4 demonstrate the vertical profiles of the logarithm of the absolute value of HCD averaged over the whole domain for these three experiments. There is a definite similarity among the experimental results. The absolute values for HCD for the whole $2000 \mathrm{~m}$ column are: $-120 \times 10^{20} \mathrm{~J},-113 \times 10^{20} \mathrm{~J}$ and $-92 \times 10^{20} \mathrm{~J}$ for the experiments $W, H, Q$, respectively. In all three profiles there are maxima in the upper $1000 \mathrm{~m}$, corresponding to the highest negative values of the HCD, especially at the depth of about $100-200 \mathrm{~m}$ and $600 \mathrm{~m}$, and a minima of the HCD occur at the depth of $1400 \mathrm{~m}$. Profiles are close to each other, especially the $W$ and $H$ experiments. The profiles of the SCD also seem to be similar, especially in the upper $600 \mathrm{~m}$. The values of the SCD at the depth in between the surface and $2000 \mathrm{~m}$ are: $17 \times 10^{13} \mathrm{~kg}, 15 \times 10^{13} \mathrm{~kg}$, and $12 \times 10^{13} \mathrm{~kg}$, respectively. Figure 5 show profiles of the correlations between HCD for the experiments $W$ and either $H$ (i.e. $W-H$ ), or $Q$ (i.e. $W-Q$ ). The correlations are reasonably high, especially in the upper $600 \mathrm{~m}$ (more than 0.8 and 0.65 in the $W-H$ and $W-Q$ experiments, respectively). The correlations between SCD for $W-H$ and $W-Q$ experiments in the upper $600 \mathrm{~m}$ are also high, more than 0.7 and 0.5 , respectively.

In the mid depth (i.e. between 500 and $1600 \mathrm{~m}$ ) correlations are weaker (see Fig. 5). In the lower layer (1600$2000 \mathrm{~m}$ ) correlations are increased because of more homogeneous distributions of temperature and salinity. All these correlations of HCD and SCD are statistically significant at 

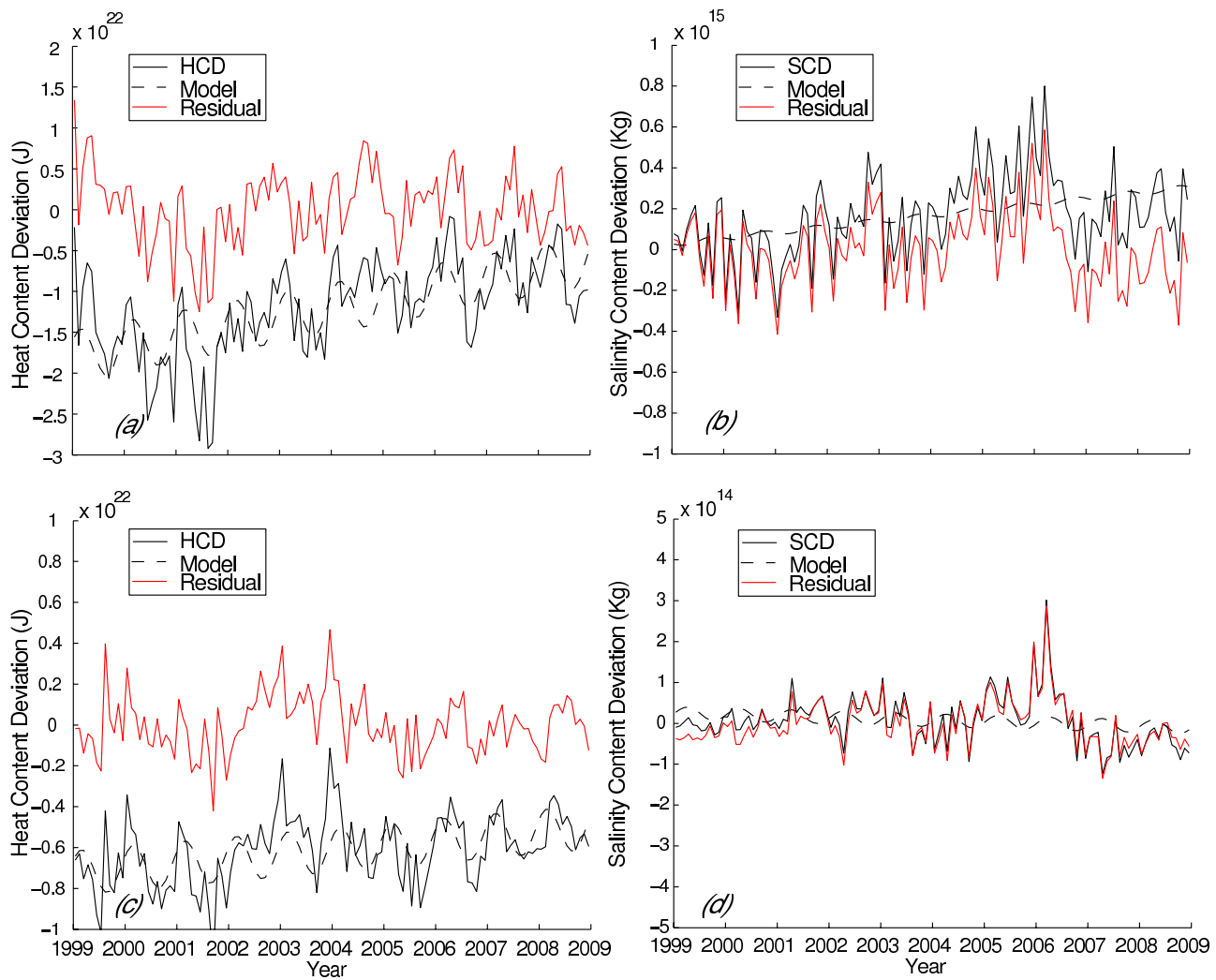

Fig. 6. Heat and salinity contents deviations, LTPO model and residual part: (a) HCD for the whole basin between 0 and $2000 \mathrm{~m}$; (b) - SCD for the whole basin between 0 and $2000 \mathrm{~m}$; (c) - HCD for the belt between $20^{\circ} \mathrm{N}$ and $30^{\circ} \mathrm{N}$ between 0 and $2000 \mathrm{~m}$; (d) - SCD for the belt between $20^{\circ} \mathrm{N}$ and $30^{\circ} \mathrm{N}$ between 0 and $2000 \mathrm{~m}$;

the $95 \%$ level of significance except for the lowest layer between 1750-2000 $\mathrm{m}$ for the $W-Q$ experiment.

\section{Deviations of heat and salinity contents and their trends}

The variability of heat and salinity contents are quite substantial for the HCD and for the SCD for the whole domain and the subdomains, as well as for different layer depths.

The strongest signal is associated with the seasonal cycle and as previously mentioned in Sect. 2, both the HCD and SCD datasets were analysed with and without the seasonal cycle to produce trends. The best fit of variability for HCD and SCD may not necessarily be just a linear fit, it could have a periodical (sinusoidal) signal or more complicated nonlinear type of variability. The latter would most likely require a longer time series than we have. Therefore, we applied two models, i.e. the linear trend (LT) model, and sinusoidal plus linear trend (LTPO) model, based on a least square approach in order to explain HCD/SCD variability.

There is a very strong seasonal cycle of temperature in upper layers. If the climatological seasonal cycle differs systematically from the seasonal cycle of the Argo observations, as happens in our case, then the HCD can retain part of the seasonal cycle signal. For example, let us suppose that climatology has a seasonal cycle of temperature (heat content) that is equal to $A_{1} \cdot \sin \omega t$, where $A_{1}$ is the amplitude, $\omega$ is an annual frequency, and $t$ is time. Let also suppose that the seasonal cycle from observational platform has the same frequency $\omega$, but different amplitude $A_{2}$, i.e. $A_{2} \cdot \sin \omega t$. The total observational signal is $B+A_{2} \cdot \sin \omega t$. The anomaly is $B+A_{2} \cdot \sin \omega t-A_{1} \cdot \sin \omega t=B+\left(A_{2}-A_{1}\right) \cdot \sin \omega t$. If $\left(A_{2}-A_{1}\right)$ is large enough compared to $B$ the major seasonal cycle is visible. In our case $\left(A_{2}-A_{1}\right)$ is about $15 \%$ of the climatology signal. Similar profound seasonal variability of temperature anomalies in upper layers were found by Resnyansky et al. (2010). The seasonal cycle of the HCD is warmer in winter and colder in summer.

The highest percentage of variance explained (PVE) corresponds to seasonal variability. The seasonal variability is stronger for HCD, than for SCD for the whole North Atlantic (Fig. 6). The PVE are equal to $42.8 \%, 37.9 \%$ and $25.6 \%$ for the HCD of the whole Northern Atlantic for the upper $2000 \mathrm{~m}$ for the $W, H$ and $Q$ experiments, respectively.

Trends of the HCD are $11.1 \cdot 10^{20}, 12.0 \cdot 10^{20}, 9.4 \cdot$ $10^{20} \mathrm{~J} / \mathrm{yr}$, for $W, H$, and $Q$, respectively. The amplitudes of seasonal variability are reasonably close to each other and statistically significant at $95 \%$ level, as well as the trends (see 

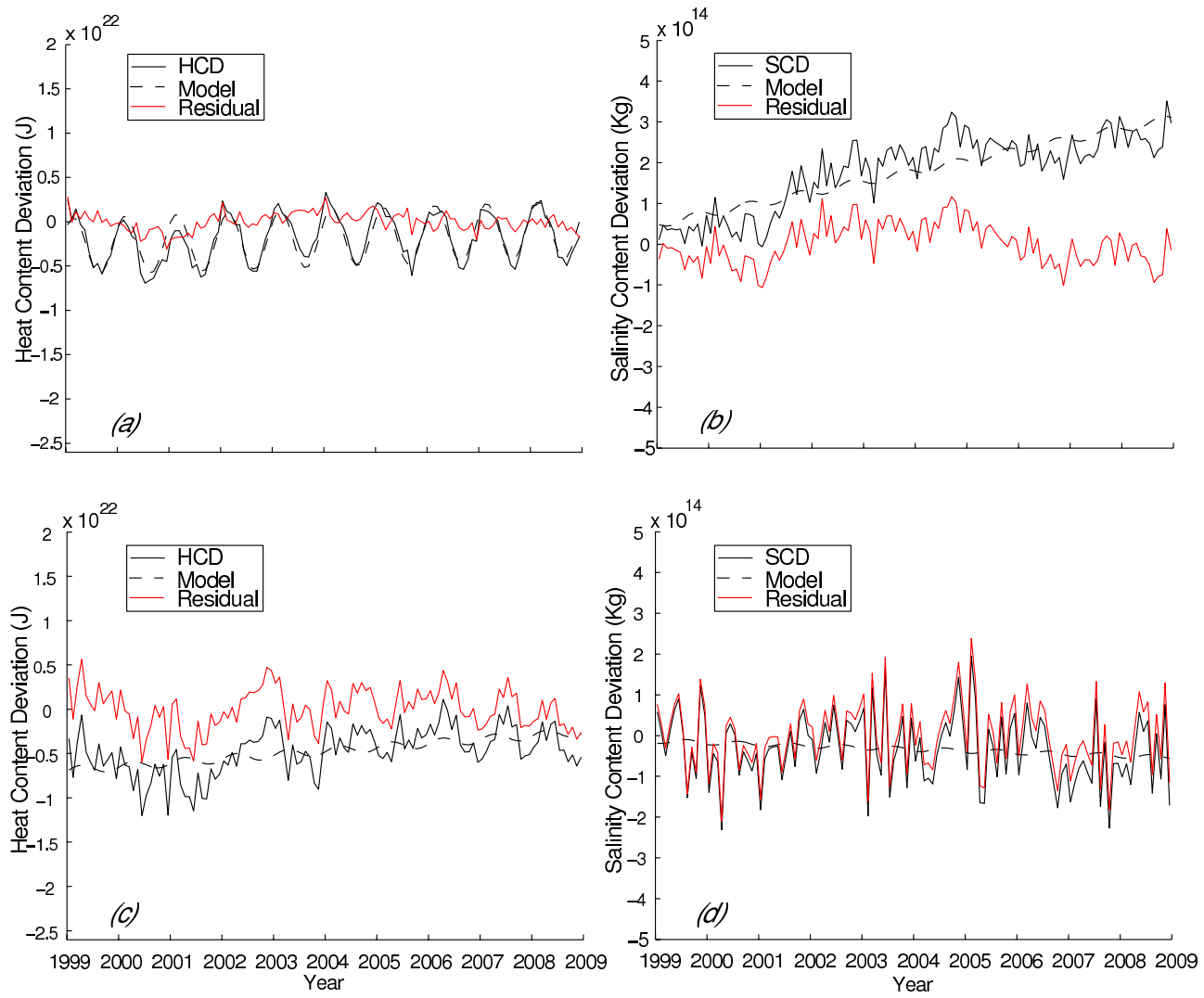

Fig. 7. Heat and salinity contents deviations, LTPO model and residual part: (a) HCD for the whole basin between 0 and $100 \mathrm{~m}$; (b) - SCD for the whole basin between 0 and $100 \mathrm{~m}$; (c) - HCD for the whole basin between 100 and $500 \mathrm{~m}$; (d) - SCD for the whole basin between 100 and $500 \mathrm{~m}$;

Table 1. HCD for the whole basin between 0 and 2000m; the uncertainty is at the $95 \%$ confidence level.

\begin{tabular}{ccccc}
\hline HCD & $\begin{array}{c}\text { Trend in LT } \\
10^{20}(\mathrm{~J} / \mathrm{yr})\end{array}$ & $\begin{array}{c}\text { Trend in LTPO } \\
10^{20}(\mathrm{~J} / \mathrm{yr})\end{array}$ & $\begin{array}{c}\text { Amplitude } 10^{20} \mathrm{~J} \\
T=1 \mathrm{yr}, \text { Eq. }\end{array}$ & $\begin{array}{c}\text { PVE } \\
(\%)\end{array}$ \\
\hline Exp. $W$ & $11.1 \pm 3.2$ & $11.7 \pm 2.9$ & $31.2 \pm 15.9$ & 42.8 \\
Exp. $H$ & $12.0 \pm 3.6$ & $12.5 \pm 3.3$ & $30.3 \pm 18.5$ & 37.9 \\
Exp. $Q$ & $9.4 \pm 3.8$ & $9.9 \pm 3.7$ & $28.4 \pm 19.9$ & 25.6 \\
\hline
\end{tabular}

Tables 1, 2). Comparing the linear trends between the two models (i.e., LTPO and LT) show that they are close to each other for the $\mathrm{W}$ experiment $11.7 \cdot 10^{20} \mathrm{~J} / \mathrm{yr}$ vs $11.1 \cdot 10^{20} \mathrm{~J} / \mathrm{yr}$, respectively.

In general, the upper ocean has a stronger seasonal cycle, compared with deeper layers (Fig. 7). The percentage of variance explained for the HCD in the upper $100 \mathrm{~m}$ is very high: $84.2 \%$ (see Table 3). The amplitude of the seasonal oscillation is much higher than the trend, i.e. $32.7 \cdot 10^{20} \mathrm{~J}$ vs. $2.0 \cdot 10^{20} \mathrm{~J}$ for 1 year. The linear trend from LT is $1.5 \cdot 10^{20} \mathrm{~J} / \mathrm{yr}$, which is smaller than predicted by LTPO model (see Table 3). The LT trend in this case is not statistically significant because of a high seasonal signal as in- dicated by the corresponding PVE value of the LTPO model. Thus the trend in the upper $100 \mathrm{~m}$ using the LTPO model is reliable.

The PVE in the deeper layers drops rapidly, which indicates seasonal variability weakens with depth (see Table 3 ). The amplitudes are decreasing for about order of magnitude and are comparable to trend for one year.

Comparing SCD for the $W, H$, and $Q$ experiments show rather small PVE (i.e. between $16.2 \%$ and $23.3 \%$ ), but stable and statistically significant trends for LTPO model: $(2.8 \pm$ $1.2) \cdot 10^{13} \mathrm{~kg},(3.5 \pm 1.2) \cdot 10^{13} \mathrm{~kg},(3.2 \pm 1.2) \cdot 10^{13} \mathrm{~kg}$, respectively. The linear trend from LT model is $(2.8 \pm 1.2)$. $10^{13} \mathrm{~kg}$ for the $W$ experiment. 
Table 2. SCD for the whole basin between 0 and $2000 \mathrm{~m}$; the uncertainty is at the $95 \%$ confidence level.

\begin{tabular}{ccccc}
\hline SCD & $\begin{array}{c}\text { Trend in LT } \\
10^{13}(\mathrm{Kg} / \mathrm{yr})\end{array}$ & $\begin{array}{c}\text { Trend in LTPO } \\
10^{13}(\mathrm{Kg} / \mathrm{yr})\end{array}$ & $\begin{array}{c}\text { Amplitude } 10^{13} \mathrm{Kg} \\
T=1 \mathrm{yr}, \text { Eq. }(1)\end{array}$ & $\begin{array}{c}\text { PVE } \\
(\%)\end{array}$ \\
\hline Exp. $W$ & $2.8 \pm 1.2$ & $2.8 \pm 1.2$ & $1.4 \pm 1.1$ & 16.2 \\
Exp. $H$ & $3.6 \pm 1.2$ & $3.5 \pm 1.2$ & $3.5 \pm 3.5$ & 23.3 \\
Exp. $Q$ & $3.3 \pm 1.2$ & $3.2 \pm 1.2$ & $3.4 \pm 3.4$ & 21.3 \\
\hline
\end{tabular}

Table 3. HCD for the whole basin at different layers; the uncertainty is at the $95 \%$ confidence level.

\begin{tabular}{ccccc}
\hline HCD & $\begin{array}{c}\text { Trend in LT } \\
10^{20}(\mathrm{~J} / \mathrm{yr})\end{array}$ & $\begin{array}{c}\text { Trend in LTPO } \\
10^{20}(\mathrm{~J} / \mathrm{yr})\end{array}$ & $\begin{array}{c}\text { Amplitude } 10^{20} \mathrm{~J} \\
T=1 \mathrm{yr}, \mathrm{Eq} .(1)\end{array}$ & $\begin{array}{c}\text { PVE } \\
(\%)\end{array}$ \\
\hline $0-100 \mathrm{~m}$ & $1.5 \pm 1.6$ & $2.0 \pm 0.6$ & $32.7 \pm 3.7$ & 84.2 \\
$100-500 \mathrm{~m}$ & $4.3 \pm 1.5$ & $4.4 \pm 1.5$ & $4.9 \pm 3.8$ & 23.5 \\
$500-1000 \mathrm{~m}$ & $4.1 \pm 1.2$ & $4.1 \pm 1.2$ & $2.7 \pm 2.3$ & 30.0 \\
$1000-2000 \mathrm{~m}$ & $1.2 \pm 0.9$ & $1.2 \pm 0.9$ & $4.4 \pm 3.2$ & 9.9 \\
\hline
\end{tabular}

Similar to HCD, there is a high PVE values for SCD in the upper ocean, where $69.6 \%$ for the upper $100 \mathrm{~m}$ is found (see Table 4; Fig. 6c). Like the HCD, the PVE drops dramatically in the lower layers i.e. between $9.6 \%$ and $2.1 \%$ for the SCD. In the upper $100 \mathrm{~m}$ and in the layer between $100 \mathrm{~m}$ to $500 \mathrm{~m}$ trends are similar for LTPO and LT models and statistically significant, but below $500 \mathrm{~m}$ they are similar, but insignificant.

When the HCD and SCD were separated into six $10^{\circ}$ zonal belts, we found that the PVE for the LTPO model showed low values (Tables 5, 6). The highest values of PVE of HCD relates to belts between $20^{\circ} \mathrm{N}-30^{\circ} \mathrm{N}(31.8 \%)$, and for the northern belts between $50^{\circ} \mathrm{N}-60^{\circ} \mathrm{N}(38.8 \%)$ and $60^{\circ} \mathrm{N}-70^{\circ} \mathrm{N}(40.4 \%)$. For the SCD the highest values of PVE correspond to the northern belts between $50^{\circ} \mathrm{N}-60^{\circ} \mathrm{N}$ $(36.2 \%)$ and $60^{\circ} \mathrm{N}-70^{\circ} \mathrm{N}(57.2 \%)$. These lower values of PVE indicate that the LTPO model does not represent the variability well because of the significance of other processes that affect the variability which is not related to the seasonal cycle and the linear trend.

Most of the time the HCD was negative, i.e. the ocean was colder than the Levitus climatology (Fig. 8). The strongest contribution to the total HCD in the upper $2000 \mathrm{~m}$ comes from the layers between $350 \mathrm{~m}$ and $900 \mathrm{~m}$ (see also Ivchenko et al., 2006).

The negative HCD for the top $2000 \mathrm{~m}$ occurs in the southern and mid North Atlantic (between $10^{\circ} \mathrm{N}$ and $50^{\circ} \mathrm{N}$ ) and positive HCD occurs in the northern North Atlantic (between $50^{\circ} \mathrm{N}$ and $70^{\circ} \mathrm{N}$ ), where the positive (warming) trend can be seen (see Fig. 9, Table 5). There appears to be a strong interannual variability with periods of a few years (Figs. 8, 9). Further analysis for periods between two to five years (limited to five years due to the Nyquist frequency) revealed

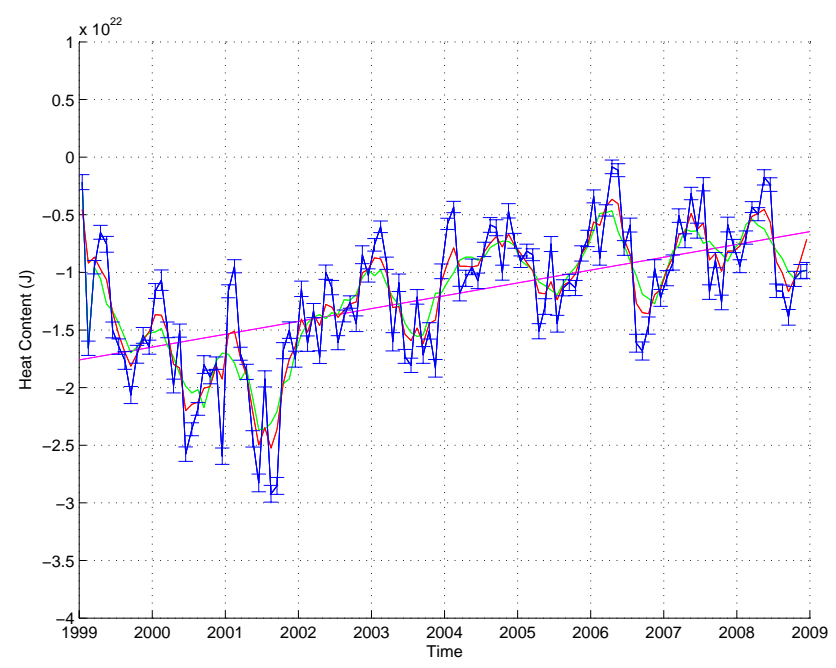

Fig. 8. HCD for the layer between 0 and $2000 \mathrm{~m}$. The vertical bars represent one standard deviation. Blue is $\mathrm{HCD}$, green is a moving averaged HCD and red is the HCD filtered with a 7 point low pass filter. The magenta represents a linear regression.

that contributions of these regions to the total variability are rather small. We suggest that the variability is a combination of different periods including periods of more than five years, and this requires a longer time series to do the analysis.

In the top $100 \mathrm{~m}$ the whole North Atlantic ocean has a strong seasonal variability (Fig. 10). In the layer between $100 \mathrm{~m}$ and $500 \mathrm{~m}$ there are some seasonal fluctuations, but not so regular as in the upper $100 \mathrm{~m}$ (Fig. 10).

The dynamics in the western and eastern North Atlantic separated by Mid Atlantic Ridge is quite different, especially because of the influence of the Gulf Stream in the western 
Table 4. SCD for the whole basin at different layers; the uncertainty is at the $95 \%$ confidence level.

\begin{tabular}{ccccc}
\hline SCD & $\begin{array}{c}\text { Trend in LT } \\
10^{13}(\mathrm{Kg} / \mathrm{yr})\end{array}$ & $\begin{array}{c}\text { Trend in LTPO } \\
10^{13}(\mathrm{Kg} / \mathrm{yr})\end{array}$ & $\begin{array}{c}\text { Amplitude } 10^{13} \mathrm{Kg} \\
T=1 \mathrm{yr}, \mathrm{Eq} .(1)\end{array}$ & $\begin{array}{c}\text { PVE } \\
(\%)\end{array}$ \\
\hline $0-100 \mathrm{~m}$ & $2.6 \pm 0.3$ & $2.6 \pm 0.3$ & $1.0 \pm 0.7$ & 69.6 \\
$100-500 \mathrm{~m}$ & $1.0 \pm 0.6$ & $1.1 \pm 0.6$ & $1.5 \pm 1.4$ & 9.6 \\
$500-1000 \mathrm{~m}$ & $-0.4 \pm 0.5$ & $-0.4 \pm 0.5$ & $0.6 \pm 0.6$ & 2.1 \\
$1000-2000 \mathrm{~m}$ & $-0.5 \pm 0.6$ & $-0.5 \pm 0.6$ & $1.4 \pm 1.0$ & 3.6 \\
\hline
\end{tabular}

Table 5. HCD at different latitudes; the uncertainty is at the $95 \%$ confidence level.

\begin{tabular}{ccccc}
\hline HCD & $\begin{array}{c}\text { Trend in LT } \\
10^{20}(\mathrm{~J} / \mathrm{yr})\end{array}$ & $\begin{array}{c}\text { Trend LTPO } \\
10^{20}(\mathrm{~J} / \mathrm{yr})\end{array}$ & $\begin{array}{c}\text { Amplitude } 10^{20} \mathrm{~J} \\
T=1 \mathrm{yr}, \text { Eq. }\end{array}$ & $\begin{array}{c}\text { PVE } \\
(\%)\end{array}$ \\
\hline $10^{\circ} \mathrm{N}-20^{\circ} \mathrm{N}$ & $1.4 \pm 1.1$ & $1.5 \pm 1.1$ & $5.6 \pm 3.7$ & 9.9 \\
$20^{\circ} \mathrm{N}-30^{\circ} \mathrm{N}$ & $2.0 \pm 1.0$ & $2.2 \pm 0.9$ & $11.0 \pm 5.1$ & 31.8 \\
$30^{\circ} \mathrm{N}-40^{\circ} \mathrm{N}$ & $1.4 \pm 1.5$ & $1.5 \pm 1.5$ & $4.1 \pm 4.0$ & 4.1 \\
$40^{\circ} \mathrm{N}-50^{\circ} \mathrm{N}$ & $1.4 \pm 1.4$ & $1.5 \pm 1.3$ & $10.2 \pm 7.7$ & 13.3 \\
$50^{\circ} \mathrm{N}-60^{\circ} \mathrm{N}$ & $2.8 \pm 0.7$ & $2.9 \pm 0.7$ & $3.3 \pm 3.0$ & 38.8 \\
$60^{\circ} \mathrm{N}-70^{\circ} \mathrm{N}$ & $2.1 \pm 0.5$ & $2.1 \pm 0.5$ & $1.1 \pm 0.9$ & 40.4 \\
\hline
\end{tabular}

Table 6. SCD at different latitudes; the uncertainty is at the $95 \%$ confidence level.

\begin{tabular}{ccccc}
\hline SCD & $\begin{array}{c}\text { Trend in LT } \\
10^{13}(\mathrm{Kg} / \mathrm{yr})\end{array}$ & $\begin{array}{c}\text { Trend in LTPO } \\
10^{13}(\mathrm{Kg} / \mathrm{yr})\end{array}$ & $\begin{array}{c}\text { Amplitude } 10^{13} \mathrm{Kg} \\
T=1 \mathrm{yr}, \mathrm{Eq} .(1)\end{array}$ & $\begin{array}{c}\text { PVE } \\
(\%)\end{array}$ \\
\hline $10^{\circ} \mathrm{N}-20^{\circ} \mathrm{N}$ & $-0.4 \pm 0.4$ & $-0.4 \pm 0.4$ & $1.4 \pm 1.1$ & 7.1 \\
$20^{\circ} \mathrm{N}-30^{\circ} \mathrm{N}$ & $-0.4 \pm 0.4$ & $-0.4 \pm 0.4$ & $1.6 \pm 1.1$ & 6.8 \\
$30^{\circ} \mathrm{N}-40^{\circ} \mathrm{N}$ & $1.2 \pm 0.7$ & $1.2 \pm 0.7$ & $2.3 \pm 2.1$ & 11.8 \\
$40^{\circ} \mathrm{N}-50^{\circ} \mathrm{N}$ & $0.6 \pm 0.4$ & $0.6 \pm 0.4$ & $0.2 \pm 0.1$ & 6.5 \\
$50^{\circ} \mathrm{N}-60^{\circ} \mathrm{N}$ & $0.9 \pm 0.2$ & $0.8 \pm 0.2$ & $1.3 \pm 0.8$ & 36.2 \\
$60^{\circ} \mathrm{N}-70^{\circ} \mathrm{N}$ & $0.9 \pm 0.2$ & $0.9 \pm 0.2$ & $1.3 \pm 0.9$ & 57.2 \\
\hline
\end{tabular}

part. For this reason an additional analysis were made for the western and eastern $10^{\circ}$ boxes, separated by the Mid Atlantic Ridge. There is a profound negative HCD in the upper $1000 \mathrm{~m}$ in the western parts of the southern and mid North Atlantic (up to $50^{\circ} \mathrm{N}$ ). In the southern belts (between $10^{\circ} \mathrm{N}-30^{\circ} \mathrm{N}$ ) the negative values correspond to more shallow depths (less than $200 \mathrm{~m}$ ). In the mid North Atlantic (between $30^{\circ} \mathrm{N}$ and $50^{\circ} \mathrm{N}$ ) the strong negative minima occur at a depth between $500-800 \mathrm{~m}$. The northern belts of North Atlantic $\left(50^{\circ} \mathrm{N}-70^{\circ} \mathrm{N}\right)$, in contrast with the southern and mid North Atlantic, have large positive values of HCD in the upper $500 \mathrm{~m}$.

In the deeper layers (more than $1000 \mathrm{~m}$ ) the amplitude of the HCD is much smaller than in the layer above.

In the eastern subregions there are also mainly negative values of the HCD in the southern and mid North Atlantic (between $10^{\circ} \mathrm{N}$ and $40^{\circ} \mathrm{N}$ ). However the belt between $40^{\circ} \mathrm{N}$ and $50^{\circ} \mathrm{N}$, as well as the northern North Atlantic $\left(50^{\circ} \mathrm{N}-\right.$ $70^{\circ} \mathrm{N}$ ) demonstrate positive HCD. The negative values of the HCD in the mid North Atlantic are not so profound as in the western subregions.

In the interior of the ocean away from the surface, bottom and western boundary layers, motion is mostly along isopycnals. As a result one can expect partial 'compensation' in the temperature-salinity space. That is an increase in temperature is related to an increase salinity to maintain a constant density. Similarly the increase of heat content should relate to an increase in salinity content. There are strong correlations between HCD and SCD between $200 \mathrm{~m}$ and $2000 \mathrm{~m}$ in all western $10^{\circ}$ belts. In the eastern belts such correlation is also strong for the southern belts, between $10^{\circ} \mathrm{N}$ and $30^{\circ} \mathrm{N}$ and in the uppermost north eastern belt between $60^{\circ} \mathrm{N}$ and $70^{\circ} \mathrm{N}$. In between $30^{\circ} \mathrm{N}$ and $60^{\circ} \mathrm{N}$ the correlations are statistically insignificant at the $95 \%$ level. 

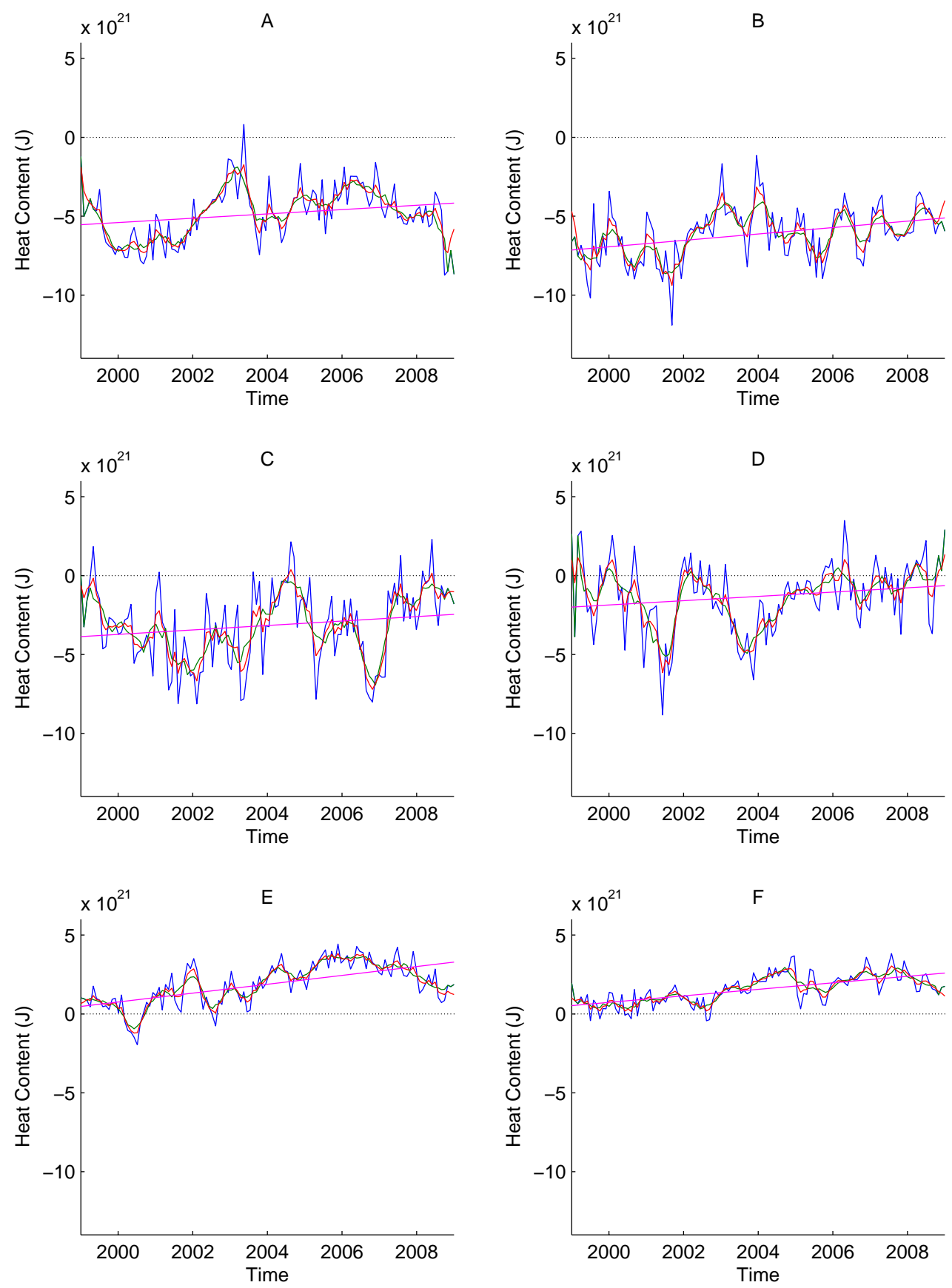

Fig. 9. Zonally integrated anomaly of heat content of the upper $2000 \mathrm{~m}$ for the $10^{\circ}$ belts: (a) between $10^{\circ} \mathrm{N}$ and $20^{\circ} \mathrm{N}$; (b) between $20^{\circ} \mathrm{N}$ and $30^{\circ} \mathrm{N}$; (c) between $30^{\circ} \mathrm{N}$ and $40^{\circ} \mathrm{N}$; (d) between $40^{\circ} \mathrm{N}$ and $50^{\circ} \mathrm{N}$; (e) between $50^{\circ} \mathrm{N}$ and $60^{\circ} \mathrm{N}$; (f) between $60^{\circ} \mathrm{N}$ and $70^{\circ} \mathrm{N}$;

Boyer et al. (2007) found that the correlation between heat and freshwater contents drops to a low value (about -0.33) in the Greenland, Iceland and Norwegian Seas.

The deviation of salinity content of the top $2000 \mathrm{~m}$ is mainly positive for the whole Northern Atlantic (Fig. 11) and in most of the $10^{\circ}$ belts (see Fig. 12). The positive trend is obvious in the northern belt between $50^{\circ} \mathrm{N}$ and $70^{\circ} \mathrm{N}(\mathrm{Ta}-$ ble 6). A similar positive trend of salinity is demonstrated by
Hatun et al., 2005 for the northern part of North Atlantic for the beginning of 21 Century.

The SCD in the top $100 \mathrm{~m}$ and in between $100 \mathrm{~m}$ and $500 \mathrm{~m}$ for the whole North Atlantic is positive with seasonal and interannual variability (see Fig. 13).

In the layer between 500 and $1000 \mathrm{~m}$ the SCD demonstrates strong fluctuation between years. The nature of such variability is not obvious, and probably it reflects a 

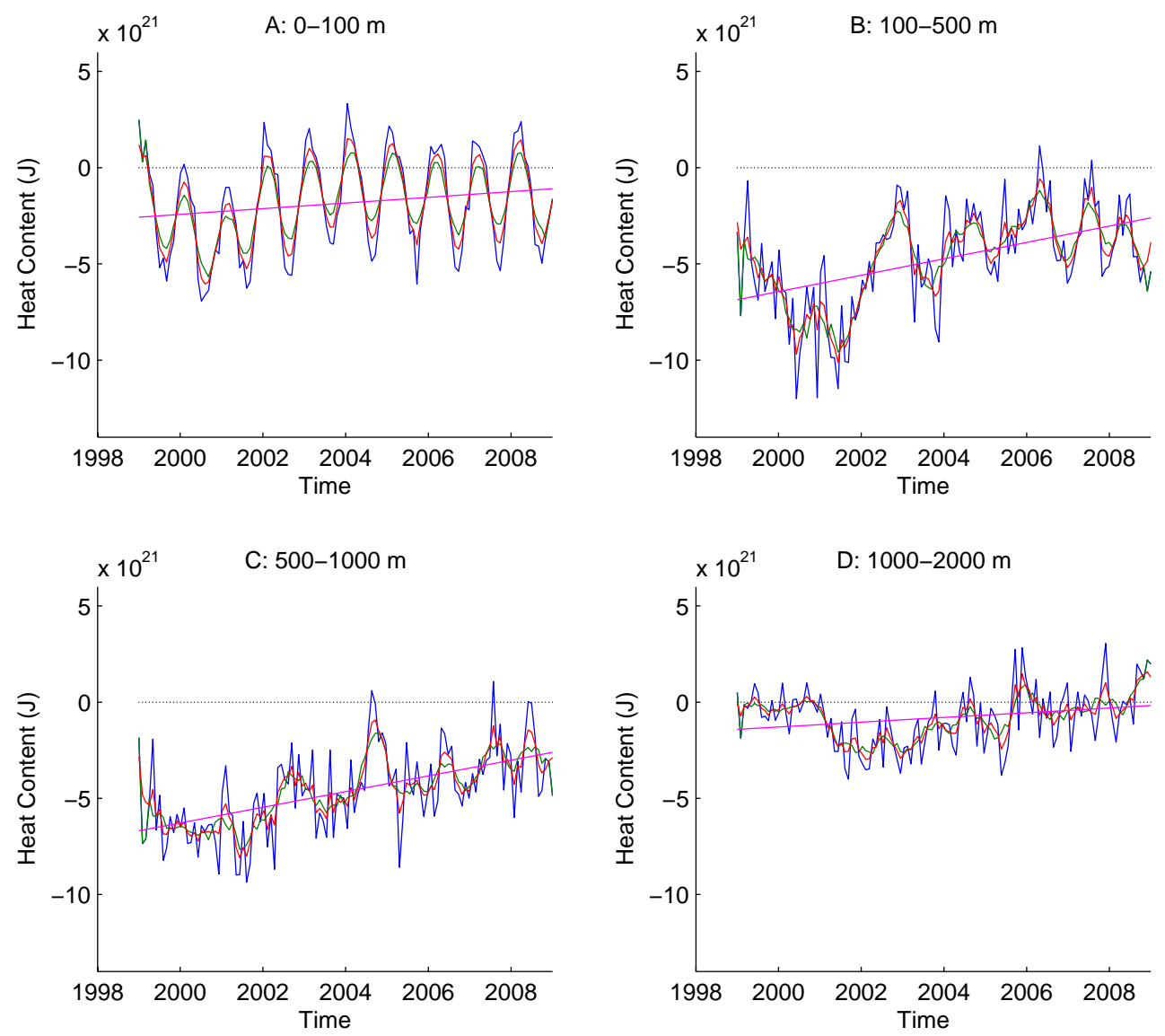

Fig. 10. HCD time series for the North Atlantic in selected layers: (a) 0-100 m; (b) 100-500 m; (c) 500-1000 m; (d) 1000-2000 m;

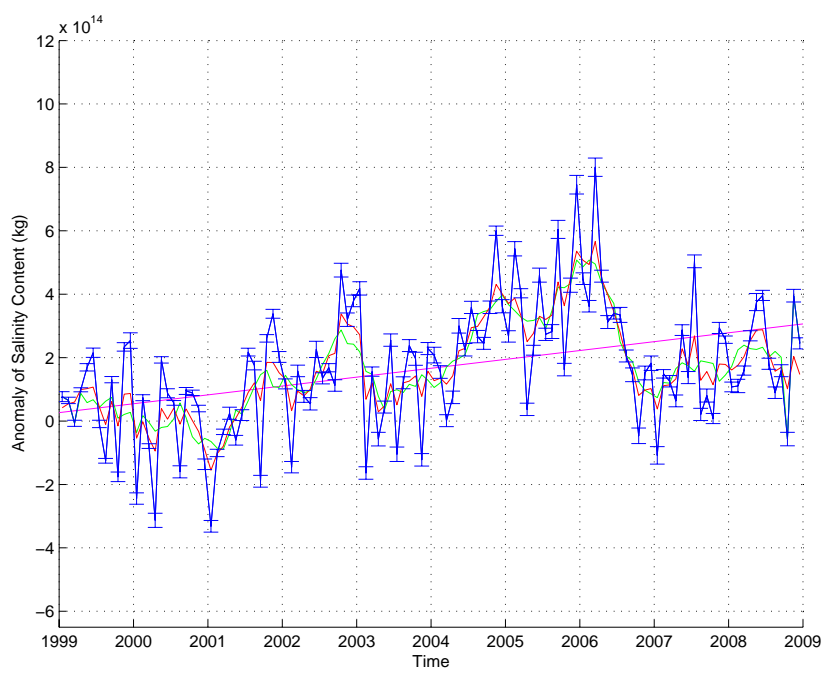

Fig. 11. SCD for the layer between 0 and $2000 \mathrm{~m}$. The vertical bars represent one standard deviation. Blue is SCD, green is a moving averaged SCD and red is the SCD filtered with a 7 point low pass filter. The magenta represents a linear regression. combination of different processes happening in subregions which have to be studied on a regional basis. In the layer between 1000 and $2000 \mathrm{~m}$ the SCD is mainly negative with strong interannual fluctuations.

\section{Summary and discussion}

The HCD demonstrate positive trends in the last 10 years in the upper $2000 \mathrm{~m}$ of the North Atlantic in all six zonal belts between $10^{\circ} \mathrm{N}$ and $70^{\circ} \mathrm{N}$. The important contribution to the trend comes from the northern part of the basin between $50^{\circ} \mathrm{N}$ and $70^{\circ} \mathrm{N}$. In the southern and central parts of the North Atlantic there is a profound interannual variability. The strongest variability occurs in the central North Atlantic. All trends for the LT are significant at $95 \%$ confidence level, except between $30^{\circ} \mathrm{N}$ and $40^{\circ} \mathrm{N}$ and between $40^{\circ} \mathrm{N}$ and $50^{\circ} \mathrm{N}$, where the strong interannual variability occurred. The trends of the LTPO are similar to the LT trends, but between $40^{\circ} \mathrm{N}$ and $50^{\circ} \mathrm{N}$ it is significant (Table 5). Levitus et al. (2009) found a decrease in heat content in the $700 \mathrm{~m}$ upper Atlantic after 2005-2006. This agrees with our findings showing decrease of heat content in the Northern Atlantic's upper $700 \mathrm{~m}$ between January 2006 and December 2008 . 

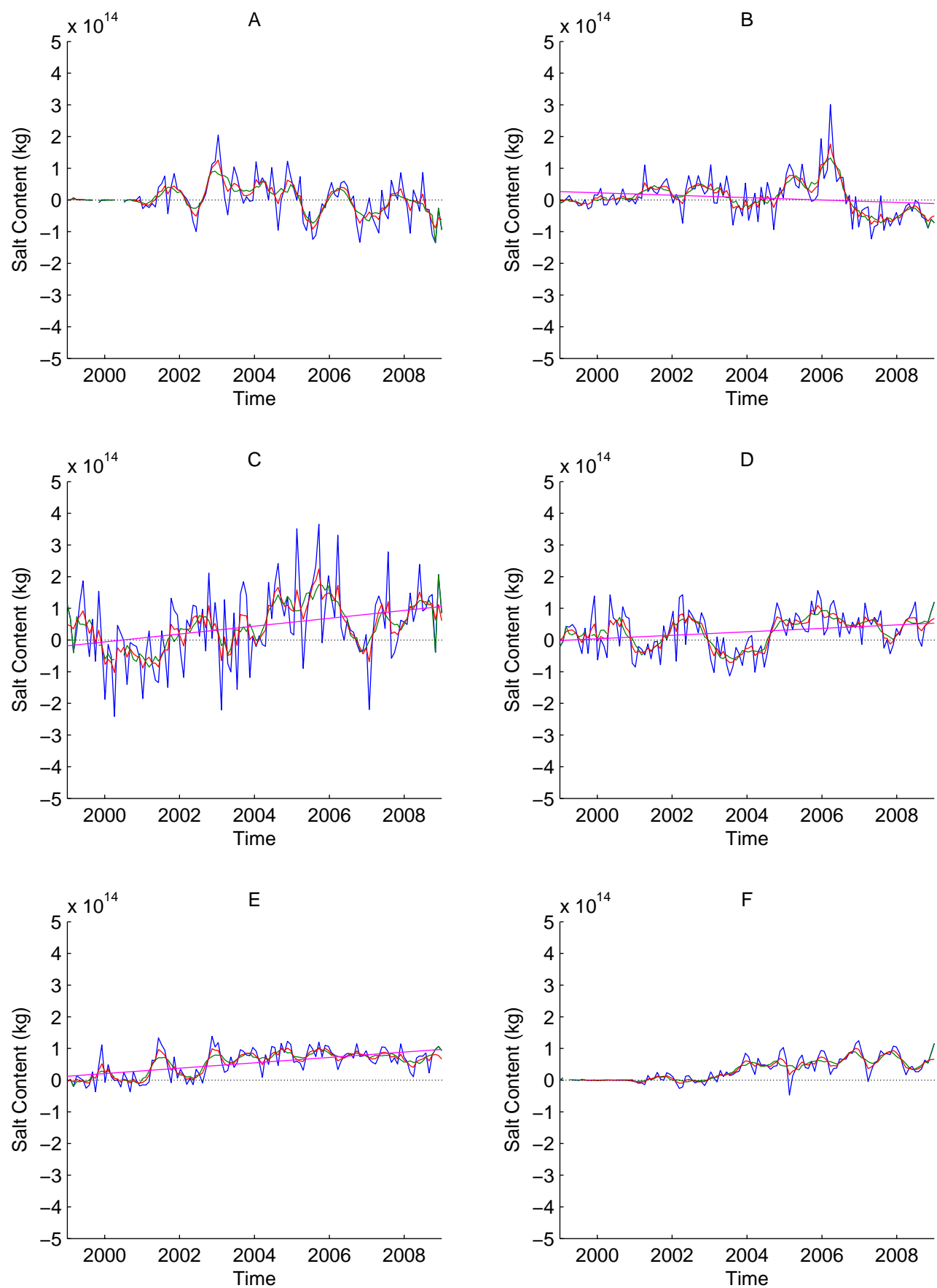

Fig. 12. Zonally integrated anomaly of salinity content of the upper $2000 \mathrm{~m}$ for the $10^{\circ}$ belts: (a) between $10^{\circ} \mathrm{N}$ and $20^{\circ} \mathrm{N}$; (b) between $20^{\circ} \mathrm{N}$ and $30^{\circ} \mathrm{N}$; (c) between $30^{\circ} \mathrm{N}$ and $40^{\circ} \mathrm{N}$; (d) between $40^{\circ} \mathrm{N}$ and $50^{\circ} \mathrm{N}$; (e) between $50^{\circ} \mathrm{N}$ and $60^{\circ} \mathrm{N}$; (f) between $60^{\circ} \mathrm{N}$ and $70^{\circ} \mathrm{N}$;

However, this negative trend is not statistically significant $\left(-4.8 \pm 8.7 \cdot 10^{20} \mathrm{~J}\right)$ in the LTPO model.

The trend of the SCD is positive (salinification) for the whole North Atlantic, but in the southern parts between $10^{\circ} \mathrm{N}$ and $30^{\circ} \mathrm{N}$ the linear trends of SCD show freshening. All these trends are statistically significant at $95 \%$ level, except between $20^{\circ} \mathrm{N}$ and $30^{\circ} \mathrm{N}$. The magnitude of freshening is much smaller than the increase in the salinity content in the north. This result agrees with Hatun et al. (2005) and Holliday et al. (2008). The latter study demonstrates a reverse of the freshening trend in the northeast North Atlantic and Nordic Seas in 1960s-1990s. In 2003-2006 salinity reached its maximum value from the 1960s and temperature exceeded records. 

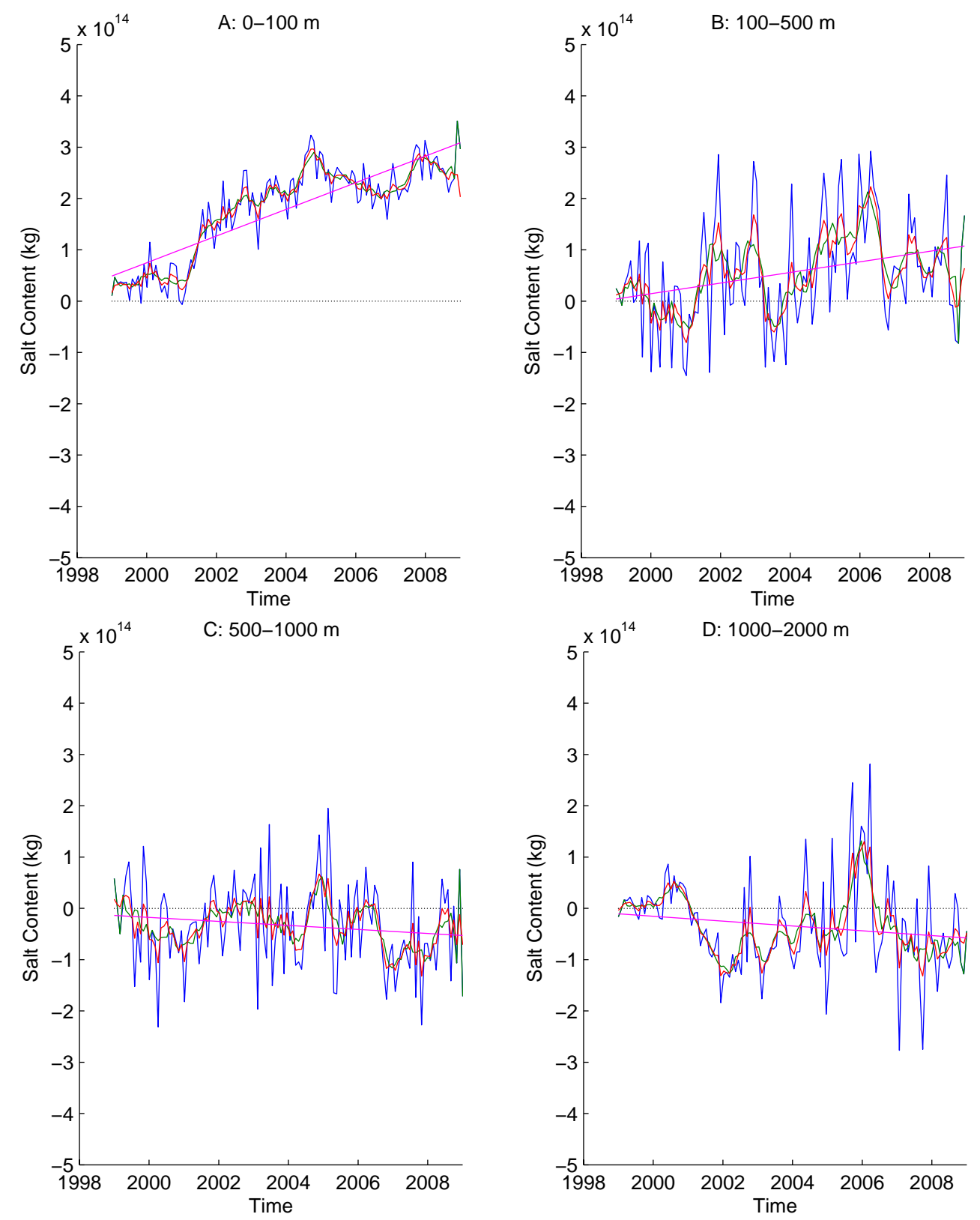

Fig. 13. SCD time series for the North Atlantic in selected layers: (a) 0-100 m; (b) 100-500 m; (c) 500-1000 m; (d) 1000-2000 m;

The average values of the HCD and SCD for the whole period of time for the upper $2000 \mathrm{~m}$ are negative for $\mathrm{HCD}$ and positive for SCD.

The negative values of the HCD are unexpected, because in a number of studies a warming of the ocean well into 2000s was observed. The most reliable explanation for this is the use of mechanical and expendable bathythermograph data resulting in a possible bias in the climatology (Gouretski and Koltermann, 2007). Gouretski and Reseghetti (2010) developed a new bias correction scheme and estimated the uncertainty in the global ocean heat content for the upper $700 \mathrm{~m}$ due to the bias in the XBT data to be about $4.5 \times 10^{22} \mathrm{~J}$. They also point out, that different corrections should be applied for different geographical regions, because of the different mean temperature distribution. Comparing quasi-collocated CTD and XBT data globally they confirmed a substantial persistent warm temperature bias. Since XBT data contributed substantially to the data set in the North Atlantic from 1970 this warm bias may have a significant influence on the climatological temperature and therefore result in a negative $\mathrm{HCD}$ in our calculations.

Wijffels et al., 2008 shows that heat content has much weaker variability in the 1970s and higher rate of change for 1961 to 2003, if one uses the data corrected for the XBT bias. 
Note, that the negative sign of the HCD occurs not everywhere, but only in the southern and central regions whilst it is positive in the northern regions. We have to be cautious when comparing results of temperature and heat content variability, because the latter depends not only on temperature, but also on the volume of the region. Thus, calculating the total heat content deviation (HCD) for the whole North Atlantic, requires weighting factors to be taken into an account for different volumes within subregions. The southern and central subdomains are weighted more than the northern subdomain, since the volume of the upper $2000 \mathrm{~m}$ layer is larger for southern and central regions. Chang et al. (2009) produced a new World Ocean atlas of monthly temperature and salinity, based on profiles for 2003-2007. In order to compare their results with ours we calculated the temperature deviation for the Northern Atlantic for the period of 2003-2007 for a similar depth, as Chang et al. (2009) on Fig. 5d (i.e. for the upper $25 \mathrm{~m}$ (our study) vs. $10 \mathrm{~m}$ (Chang et al., 2009). Both distributions were in good agreement, i.e., the positive temperature anomalies in the upper ocean occurred in the most parts of the North Atlantic, especially high in the north west region. However, in the mid depths there appears to be a discrepancy with Chang et al.'s, 2009) work, where we found averaged HCD values to be negative, while Chang et al. (2009) demonstrate positive values (of averaged temperature). It is unclear why this discrepancy occurred. The HCD calculation methods, including objective analysis schemes, can be a factor in this difference. Intercomparison of the methods, including their parameters, used for the estimation of heat content should be considered in future work.

The values of HCD and SCD are dependent on the climatology. Therefore if there is some bias in the climatological data due to XBT (or other problems) will affect $\mathrm{HCD} / \mathrm{SCD}$ values, but not the trends, because the bias is automatically eliminated when calculating the trends.

Seasonal variability of the HCD in the upper $100 \mathrm{~m}$ is much clearer than the variability of the SCD. There is a positive trend of the HCD in the basin averaged upper ocean (0-100 m, 100-500 m, 500-1000 $\mathrm{m}$ and 1000-2000 m). The SCD demonstrates a positive trend in the upper $100 \mathrm{~m}, 100$ $500 \mathrm{~m}$, but a negative trend between $500-1000 \mathrm{~m}$ and 1000 $2000 \mathrm{~m}$ was found.

The important question for any interpretation of observations in a basin-wide domain is: is the number of observations and their density population good enough for the estimations, based on such data? We have to understand what kind of estimation we are looking for. That is, do we associate this estimation with a local subregion, or for a large scale region? On a local scale in some particular places there are only few (if ever) observations at certain times and according to our methods the result would be close to the climatology. However, for the basin-averaged values the Argo data provides a stable base for the estimation of the HCD, and to some extent SCD. Removing half of the data leads to values not too far from the total set. In most parts of the upper
$2000 \mathrm{~m}$ the time averaged HCD are statistically significant, as well as the time dependent series of the depth averaged HCD. There are clear signs of the negative HCD in the upper $1000 \mathrm{~m}$ in most parts of the southern and mid North Atlantic. There is also evidence for a positive sign of the HCD in the northern part of the North Atlantic.

Our calculations for the HCD and SCD are based on $10^{\circ}$ boxes. Using finer spatial resolution (for example $1^{\circ}$ ) temperature and salinity fields demonstrates much more patchiness (see Ivchenko et al., 2007, 2008). We should add the caveat about the salinity data, where in the southernmost and northernmost regions had lower number of salinity observations in the first three years.

In the future we expect that the uncertainty of temperature and salinity to be reduced due to increasing number of observations and improved technology. In addition, the length of time series will increase allowing better estimates of trends.

Acknowledgements. We are grateful to Harry Bryden and Viktor Gouretski for the helpful conversations and corrections. We appreciate valuable comments from two anonymous reviewers and Dr Sarafanov. V. O. Ivchenko was supported by the National Environment Research Council (NERC, UK) as part of the Rapid Climate Change (RAPID-WATCH) Programme. This work complements the British NERC Programme Oceans 2025.

Edited by: M. Hecht

\section{References}

Boyer, T., Levitus, S., Antonov, J.I., Locarnini, R., Mishonov, A., Garcia, H., and Josey, S.: Changes in freshwater content in the North Atlantic Ocean 1955-2006, Geophys. Res. Lett., 34, L16603, doi:10.1029/2007GL030126, 2007.

Bretherton, F. P., Davis, R. E., and Fandry, C. B.: A technique for objective analysis and design of oceanographic experiments applied to MODE-73, Deep-Sea Res., 23, 559-582, 1976.

Chang, Y. S., Rosati, A. J., Zhang, S., and Harrison, M. J.: Objective analysis of monthly temperature and salinity for the world ocean in the 21st century: Comparison with World Ocean Atlas and application to assimilation validation, J. Geophys. Res., 114, C02014, doi:10.1029/2008JC004970, 2009.

Coatanoan, C. and De La Villeon, L. P.: In-situ data quality control procedures. Coriolis Data Centre. CORDO/DTIRAP/04-047.P17, http://www.coriolis.eu.org//cdc/ documents/cordorap-04-047-quality-control.pdf, 2005.

Curry, R. G., McCartney, M. S., and Joice T. M.: Oceanic transport of subpolar climate signals to mid-depth subtropical waters, Nature, 391, 575-577, 1998.

Curry, R. G. and Mauritzen, C.: Dilution of the Northern North Atlantic Ocean in recent decades, Science, 308, 1772-1774, 2005.

Dickson, R., Lazier, J., Meinke, J., Rhines, P., and Swift, J.: Longterm coordinated changes in the convective activity of the North Atlantic, Prog. Oceanogr., 38(3), 241-295, 1996.

Dickson, R., Yashayaev, I., Meincke, J., Turrell, W., and Dye, S.: Rapid freshening of the deep North Atlantic Ocean over the past four decades, Nature, 416, 832-837, 2002. 
Emery, W. J. and Thomson, R. E.: Data analysis methods in Physical Oceanography. Oxford: Pergamon Press, 634 pp., 1998.

Folland, C. K., Rayner, N. A., Brown, S. J., et al.: Global temperature change and its uncertainties since 1861, Geophys. Res. Lett., 28, 2621-2624, 2001.

Gandin, L. S.: Objective analysis of meteorological fields. Israel Program for Scientific Translations, 242 pp., 1965.

Gouretski, V. and Koltermann, K. P.: How much is the ocean really warming? Geophys. Res. Lett., 34, L01610, doi:10.1029/2006GL027834, 2007.

Gouretski, V. and Reseghetti, F.: On depth and temperature biases in bathythermograph data: Development of a new correction scheme based on analysis of a global ocean database, Deep-Sea Res., 1, doi:10.1016/j.dsr.2010.03.011, 2010.

Hatun, H., Sando, A.B., Drange, H., Hansen, B., and Valdimarsson, H.: Influence of the Atlantic Subpolar Gyre on the thermohaline circulation, Science, 309, 1841-1844, 2005.

Holliday, N. P., Hughes, S. L., Bacon, S., Beszczynska-Moeller, A., Hanses, B., Lavin, A., Loeng, H., Mork, K. A., Osterhus, S., Shervin, T., and Walczowski, W.: Reversal of the 1060s to 1990s freshening trend in the northeast North Atlantic and Nordic Seas, Geophys. Res. Lett., 35, L03614, doi:10.1029/2007GL032675, 2008

Ivchenko, V. O., Wells, N. C., and Aleynik, D. L.: Anomaly of heat content in the northern Atlantic in the last 7 years: is the ocean warming or cooling?, Geophys. Res. Lett., 33, L22606, doi:10.1029/2006GL027691, 2006.

Ivchenko, V. O., Danilov, S. D., Sidorenko, D. V., Schröter, J., Wenzel, M., and Aleynik, D. L.: Comparing the steric height in the Northern Atlantic with satellite altimetry, Ocean Sci., 3, 485490, doi:10.5194/os-3-485-2007, 2007.

Ivchenko, V. O., Danilov, S., Sidorenko, D., Schroeter, J., Wenzel, M., and Aleynik, D. L.: Steric height variability in the Northern Atlantic on seasonal and interannual scales, J. Geophys. Res., 113, C11007, doi:10.1029/2008JC004836, 2008.

Lavender, K. L., Owens, W. B., and Davis, R. E.: The mid-depth circulation of the subpolar North Atlantic Ocean as measured by subsurface floats, Deep-Sea Res., 52, 767-785, 2005.

Leadbetter, S. J., Williams, R. G., McDonagh, E. L., and King, B. A.: A twenty year reversal in water mass trends in the subtropical North Atlantic, Geophys. Res. Lett., 34, L112608, doi:10.1029/2007GL029957, 2007.

Levitus, S., Boyer, T. P., and Antonov, J. I.: World Ocean Atlas 1994, 5, Interannual Variability of Upper Ocean. Thermal Structure, NOAA Atlas NESDIS 5, US Government Printing Office, Washington, DC, 1994.

Levitus, S., Antonov, J. I., Boyer, T. P., and Stephens, C.: Warming of the World Ocean, Science, 287, 2225-2229, 2000.

Levitus, S., Antonov, J. I., Boyer, T. P., Locarnini, R. A., Garcia, H. E., and Mishonov, A. V.: Global ocean heat content 1955-2008 in light of recently revealed instrumentation problems, Geophys. Res. Lett., 36, L07608, doi:10.1029/2008GL037155, 2009.

Levitus, S., Antonov, J., and Boyer, T.: Warming of the world ocean, 1955-2003. Geophys. Res. Lett., 32, L02604, doi:10.1029/2004GL021592, 2005.

Lozier, M. S., Leadbetter, S., Williams, R. G., Roussenov, V., Reed, M. S. C., and Moore, N. J.: The spatial pattern and mechanisms of heat-content change in the North Atlantic, Science, 319, 800803,2008 .
Lozier, M. S., Owens, W. B., and Curry, R. G.: The climatology of the North Atlantic, Progress in Oceanography, 36(1), 1-44, 1995.

Lyman, J. M., Willis, J. K., and Johnson, G. C.: Recent cooling of the upper ocean, Geophys. Res. Lett., 33, L18604, doi:1029/2006GL027033, 2006.

Meyers, G. A., Sprintal, J., Philips, H. E., et al.: Design of an ocean temperature observing network in the seas north of Australia, Part 1. Tropical Pacific Ocean: Statistics. CSIRO Marine Laboratories Report, 204, 50 pp., 1989.

Polyakov, I. V., Bhatt, U. S., Simmons, H. L., Walsh, D., Walsh, J. E., and Zhang, X.: Multidecadal variability of North Atlantic temperature and salinity during the twentieth century, J. Climate, 18, 4562-4581, 2005.

Potter, R. A. and Lozier, M. S.: On the warming and salinification of the Mediterranean outflow waters in the North Atlantic, Geophys. Res. Lett., 31, L01202, doi:1029/2003GL018161, 2004.

Roemmich, D. and Gilson, J.: The 2004-2008 mean and annual cycle of temperature, salinity, and steric height in the global ocean from the Argo Program. Progress in Oceanography, 82, 81-100, 2009.

Resnyansky, Y. D., Tsyrulnikov, M. D., Strukov, B. S., and Zelenko, A. A.: Statistical structure of spatial variability of the ocean thermohaline fields from Argo profiling data over 20052007, Oceanology, 50, 1-19, 2010.

Sarafanov, A., Falina, A., Sokov, A., and Demidov, A.: Intense warming and salinification of intermediate waters of southern origin in the eastern subpolar North Atlantic in the 1990 s to mid-2000s. J. Geophys. Res., 113, C12022, doi:10.1029/2007JC004975, 2008.

Sarafanov, A., Sokov, A., Demidov, A., and Falina, A.: Warming and salinification of intermediate and deep waters in the Irminger Sea and Iceland Basin in 1997-2006, Geophys. Res. Lett., 34, L23609, doi:10.1029/2007GL031074, 2007.

Stephens, C., Antonov, J. I., Boyer, T. P., Conkright M. E., Locarnini, R., and O'Brien, T. D.: World Ocean Atlas 2001. 1: Temperature (CD-ROM), eds. by S. Levitus, NOAA Atlas NESDIS 49, U.S. Govt. Printing Office, Washington, D.C., 2002.

von Schukmann, K., Gaillard, F., and Le Traon, P.-Y.: Global hydrographic variability patterns during 2003-2008. J. Geophys. Res., 114, C09007, doi:10.1029/2008JC0055237, 2009.

White, W. B.: Design of a global observing system for gyre-scale upper temperature variability. Progress in Oceanography, 36, 169-217, 1995.

White, W. B. and Bernstein, R. L.: Design of an oceanographic network in the mid-latitude North Pacific, J. Phys. Oceanogr., 9, 592-606, 1979.

Wijffels, S. E., Willis, J., Domingues, C. M., Barker, P., White, N. J., Gronell, A., Ridgway, K., and Church, J. A.: Changing expendable bathythermograph fall rates and their impact on estimates of thermosteric sea level rise, J. Climate, 21, 5657-5672, 2008.

Willis, J. K., Lyman, J. M., Johnson, G. C., and Gilson, J.: In situ data biases and recent ocean heat content variability, J. Atmosph. Oceanic Tech., 26, 4, doi:10.1175/2008JTECHO608.1, 2009.

Willis J. K., Roemmich, D., and Cornuelle, B.: Interannual variability in upper ocean heat content, temperature, and thermosteric expansion on global scales, J. Geophys. Res., 109, C12036, doi:10.1029/2003JC002260, 2004. 
Wong, A., Keeley, R., Carval, T., and the Argo Data Management Team.: Argo quality control manual, Version 2.2. P.33. Coriolis Data Centre. http://www.coriolis.eu.org/cdc/argo/ argo-quality-control-manual.pdf, 2006.
Yashayaev, I.: Hydrographic changes in the Labrador Sea, 1960-2005, Progress in Oceanography, 73(3-4), 242-276, doi:10.1016/j.pocean.2007.04.015, 2007. 